\title{
PENGARUH PERTUMBUHAN KENDARAAN DAN KAPASITAS JALAN TERHADAP KEMACETAN DI RUAS JALAN PERINTIS KEMERDEKAAN
}

\author{
Lambang Basri Said ${ }^{1}$ St. Maryam. $\mathrm{H}^{2}$, Sriwati $^{3}$ \\ ${ }^{1}$ Dosen Jurusan Teknik Sipil Universitas Muslim Indonesia (UMI) \\ Jalan Urip Sumoharjo No.225 Makassar, Telp. 454534 \\ ${ }^{2}$ Dosen Jurusan Teknik Sipil Universitas Muslim Indonesia (UMI) \\ Jalan Urip Sumoharjo No.225 Makassar, Telp. 454534 \\ ${ }^{3}$ Mahasiswa Program Pascasarjana Magister Teknik Sipil UMI . \\ Jl Urip Sumoharjo No.225 Makassar,Telp.454534.hajjasriwati@gmail.com
}

\begin{abstract}
Abstrak
Kemacetan di Kota Makassar umumnya disebabkan oleh meningkatnya volume kendaraan di setiap tahun yang tidak diimbangi dengan kapasitas jalan yang tersedia, yang menyebabkan kemacetan lalu lintas. Berangkat dari masalah yang disebutkan di atas, tujuan dari penelitian ini adalah untuk mengetahui dan menganalisis pengaruh peningkatan jumlah kendaraan dan kapasitas jalan terhadap kemacetan lalu lintas di Jalan Perintis Kemerdekaan di Kota Makassar. Penelitian ini dilakukan dengan metode analisis deskriptif dan metode statistik. Dalam metode analisis deskriptif diperoleh informasi yang berisi karakteristik responden berdasarkan jenis kelamin, usia, dan tingkat pendidikan pada pernyataan dalam kuesioner. Sedangkan metode statistik pengolahan data dilakukan oleh SPSS Statistics 22.0 untuk program Windows. Hasil penelitian secara bersamaan menunjukkan bahwa peningkatan jumlah kendaraan dan kapasitas jalan secara simultan memiliki efek positif dan signifikan terhadap kemacetan lalu lintas di Jalan Perintis Kemerdekaan di Kota Makassar. Hasil penelitian secara parsial menunjukkan bahwa peningkatan jumlah kendaraan dan kapasitas jalan berpengaruh positif dan signifikan terhadap kemacetan lalu lintas dan kapasitas jalan merupakan variabel yang paling dominan mempengaruhi kemacetan lalu lintas di Jalan Perintis Kemerdekaan di Kota Makassar.
\end{abstract}

Kata Kunci: Jumlah kendaraan; kapasitas jalan; kemacetan lalu lintas.

\section{ABSTRACT}

Congestion in the city of Makassar is generally caused by the increasing volume of vehicles in each year which is not balanced with the capacity of available roads, which causes traffic congestion. Departing from the problems mentioned above, the purpose of this research is to find out and analyze the effect of increasing the number of vehicles and the capacity of the road to traffic congestion on the Perintis Kemerdekaan Road in Makassar City. This research was conducted with descriptive analysis methods and statistical methods. In the descriptive analysis method obtained information that contains the characteristics of respondents based on gender, age, and level of education on the statements in the questionnaire. While the statistical method of data processing is done by the SPSS Statistics 22.0 for Windows program. The results of the study simultaneously indicate that the increase in the number of vehicles and road capacity simultaneously has a positive and significant effect on traffic congestion on the Perintis Kemerdekaan Road in Makassar City. The results of the study partially show that the increase in the number of vehicles and road capacity has a positive and significant effect on traffic congestion and road capacity is the most dominant variable influencing traffic congestion on the Perintis Kemerdekaan Road in Makassar City.

Keywords: number of vehicles; road capacity; traffic congestion 


\section{PENDAHULUAN}

\subsection{Latar belakang}

Penyebab utama yang menyebabkan kemacetan lalu lintas adalah tingginya jumlah kendaraan yang disebabkan oleh populasi dan perkembangan ekonomi. Untuk mengatasi masalah ini, pemerintah harus mendorong orang untuk menggunakan transportasi umum atau kendaraan dengan ukuran kecil seperti sepeda atau membuat pajak atas kendaraan pribadi. Khususnya, di beberapa negara Asia seperti Vietnam, pihak berwenang setempat mengesahkan undang- undang yang membatasi jumlah kendaraan untuk setiap metode yang disebutkan di atas memang efektif pada kenyataannya untuk mengatasi kemacetan lalu lintas (Nguyen Van Thu, 2016). Kemacetan adalah keadaan dimana pada saat tertentu kendaraan yang sedang berjalan melewati suatu ruas jalan berhenti dalam waktu yang singkat maupun lama. Kemacetan merupakan bukti ketidakberesan pengaturan lalu lintas yang terjadi pada daerah perkotaan, tetapi kemacetan bukanlah sebuah fenomena baru. Hampir semua kota besar baik di negara maju maupun negara yang sedang berkembang masih menghadapi masalah kemacetan paling sedikit pada jam-jam sibuk pagi dan sore hari (Clarkson dan Gary,1988) dalam Firdausi (2016).

Salah satu penyebab utama kemacetan di Kota Makassar pertumbuhan kendaraan bermotor yang sangat cepat namun tidak sebanding dengan peningkatan kapasitas jalan yang tersedia. Tingginya angka pertumbuhan kendaraan bermotor di kota Makassar menjadi tolak ukur meningkatnya perekonomian masyarakat. Namun, di sisi lain pertumbuhan kendaraan tiap tahunnya justru berdampak terhadap tingginya volume kendaraan di jalan raya yang mengakibatkan kemacetan. Pada semester 1 tahun 2017, totalnya sudah 1,46 juta unit. Pertumbuhannya sangat tinggi dan tidak sebanding dengan pertumbuhan infrastruktur jalan. Merujuk data Samsat, kendaraan bermotor di Kota Daeng didominasi roda dua yang mencapai 1.156.759 unit. Disusul mobil penumpang (213.985 unit), mobil barang (74.603 unit) BPS Kota Makassar, (2018). Namun, jumlah tersebut belum termasuk kendaraan baru yang data pajaknya belum terdaftar. Padatnya arus lalulintas di Kota Makassar juga disebabkan banyak kendaraan bermotor yang berasal dari kabupaten atau kota bahkan provinsi lain dimana Kota Makassar menjadi pusat aktivitas di Sulawesi Selatan. Kemacetan yang selalu terjadi di Makassar, khususnya pada pagi dan sore hari disebabkan volume kendaraan yang tinggi, semakin banyak mobil murah dan terlalu gampangnya pembelian sepeda motor dan pemerintah tidak bisa membatasi pertumbuhan kendaraan (Kurniawan, 2017).

Kemacetan lalu lintas sangat sulit untuk dihilangkan, namun paling tidak dapat dikurangi kepadatannya. Hal ini dikarenakan kemacetan itu dipengaruhi oleh banyak faktor yang saling terkait satu sama lainnya. Beberapa penelitian yang mendukung kajian ini antara lain oleh Mustikarani dan Suherdiyanto (2016) melihat faktor yang menyebabkan kemacetan lalu lintas faktor jalan (lebaran jalan, volume kendaraan, jarak lampu lalu lintas yang dipasang cukup banyak dan berdekatan dan persimpangan jalan atau gang) dan faktor manusia (kegiatan pasar tradisional dan pasar modern, kegiatan parkir sembarangan). Changzhi et al. (2016) melihat luas jalan setiap kepemilikan mobil, berpengaruh signifikan terhadap rasio kemacetan. Taiwo (2018) melihat faktorfaktor seperti infrastruktur jalan yang buruk, kapasitas jalan, perdagangan jalanan, parkir di jalan dan persimpangan kapasitas tinggi telah diidentifikasi sebagai penyebab terjadinya kemacetan. Sedangkan Budi (2014) yang melihat peninkatan jumlah kendaraan bermotor yang tiak sebanding dengan pertambahan panjang jalan yang tersedia sehingga terjadi kemacetan lalu lintas yang mencapai tingkat yang sangat tinggi.

\subsection{Perumusan Masalah}

Berangkat dari permasalahan yang ada serta kajian penelitian terdahulu maka yang menjadi tujuan dalam penelitian ini adalah untuk mengetahui dan menganalis pengaruh peningkatan jumlah kendaraan dan kapasitas jalan terhadap kemacetan lalulintas di Jalan Perintis Kemerdekaan Kota Makassar, berdasarkan pengamatan dan evaluasi yang dilakukan sepanjang Jalan Printis Kemerdekaan Kota Makassar, melalui pengamatan yang dilakukan dilakukan depan Markas 
Kepolisian Daerah (Mapolda) Sulawesi Selatan, depan RS Universitas Hasanuddin dan di depan Mall M-Tos.

\subsection{Tujuan Penelitian}

Tujuan dari penelitian ini adalah untuk mengetahui dan menganalisis pengaruh peningkatan jumlah kendaraan dan kapasitas jalan terhadap kemacetan lalu lintas di Jalan Perintis Kemerdekaan di Kota Makassar.

\subsection{Hipotesis}

Diduga peningkatan jumlah kendaraan dan kapasitas jalan terhadap kemacetan lalu lintas di Jalan Perintis Kemerdekaan di Kota Makassar.

\section{METODE PENELITIAN}

\subsection{Lokasi dan Waktu Penelitian}

Penelitian ini dilakukan di ruas jalan Perintis Kemerdekaan, Kota Makassar, Provinsi Sulawesi Selatan. Pemilihan lokasi ini dilakukan setelah melakukan survey (baik secara langsung maupun tak langsung) dengan mempertimbangkan: (1) jalan Perintis Kemerdkaan merupakan ruas jalan di Kota Makassar yang mengalami kemacetan lalu lintas dari waktu ke waktu, (2) Adanya kesesuaian data yang diharapkan dapat mendukung dan mewujudkan tujuan penelitian yang diajukan. Pengambilan data primer melalui kuisioner dilakukan kurang lebih dua bulan sejak bulan Januari sampai dengan Februari 2019.

\subsection{Populasi dan Sampel}

Kriteria seorang individu yang dapat menjadi responden dalam penelitian ini adalah individu tersebut merupakan warga Kota Makassar atau pengguna jalan yang sering melintasi di Jalan. Koridor Jalan Perintis Kemerdekaan, berusia minimal 20 tahun, serta merasakan kemacetan yang terjadi di Kota Makassar.

\subsection{Metode Analisis}

Menyesuaikan dengan tujuan penelitian, maka teknik analisis data yang digunakan dalam penelitian ini adalah analisis regresi linier berganda. Analisis ini digunakan untuk mengetahui pengaruh variabel bebas terhadap variabel terikat. Untuk menentukan ada pengaruh yang signifikan antara variabel bebas terhadap variabel terikat digunakan uji statistik koefisien regresi. Model regresi liniernya (Sugiyono, 2008:183) adalah :

$\mathbf{Y}=\mathbf{b}_{0}+\mathbf{b}_{1} \mathbf{X}_{1}+\mathbf{b}_{2} \mathbf{X}_{2}+\mathbf{e}$

Dimana :

$\mathrm{Y}=$ Kemacetan Lalu Lintas

$\mathrm{X}_{1}=$ Pertumbuhan Kendaraan

$\mathrm{X}_{2}=$ Kapasitas Jalan

$\mathrm{b}_{0}=$ Konstanta

$\mathrm{b}_{1}$, dan $\mathrm{b}_{2}=$ Koefisien regresi

$\mathrm{e}=$ Standard error.

Model analisis yang digunakan dalam penelitian ini adalah analisis persamaan simultan, dengan data yang digunakan merupakan data ordinal. Model analisis yang dibangun sesuai dengan skema kerangka konseptual berikut: 


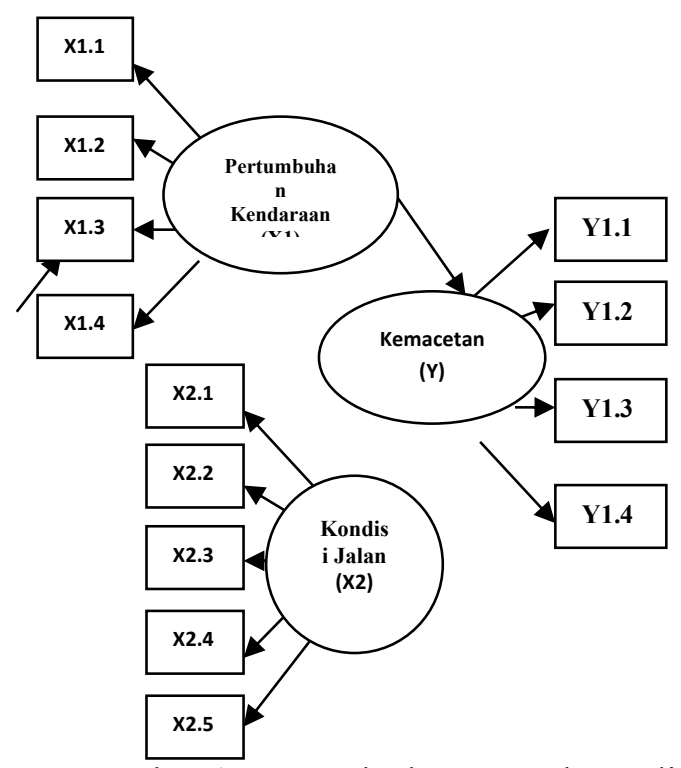

Gambar 1 Kerangka konseptual Penelitian

\section{HASIL DAN PEMBAHASAN}

\subsection{Karakteristik Responden}

Karakteristik responden, merupakan gambaran tentang umur dan jenis kelamin dan latar belakang pendidikan. Berdasarkan informasi yang disajikan dari Tabel 1 di atas, maka dapat dideskripsikan bahwa responden berdasarkan umur didominasi oleh responden berumur 30 sampai dengan 40 tahun sebesar 20,75\%, mengindikasikan tingginya kuantitas responden dengan umur produktif yang memberikan persepsi terkait penelitian ini yang disesuaikan dengan kondisi yang dirasakan sebaga dampak dari kemacetan yang dirasakan.

Berdasarkan jenis kelamin, menunjukkan respinden yang memberikan persespsinya terkait penelitian ini didominasi oleh reponden laki-laki dari berbagai kalangan mengindikasikan tingginya tingkat kuantitas pengguna jalan yang menggunakan kendaraan didominasi oleh laki-laki.

Berdasarkan dari latar belakang pekerjaan, sebagaian besar pengguna jalan yang dijadikan responden bekerja sebagai pegawai swasta dan mahasiswa dan selebihnya adalah pegawai negeri, wiraswasta dan adapula yang tidak memiliki pekerjaan.

Sedangkan berdasarkan dara dari para responden jumlah kendaraan yang dimiliki secara keseluruhan sebanyak 75 unit mobil dan 113 unit dari jenis sepeda motor. Hal ini dijelaskan lebih lanjut berdasarkan data yang terkumpul ada responden yang memiliki dua bahkan sampai 3 jenis kendaraan bermotor dalam satu rumah tangga dan ada pula yang memiliki jenis kendaraan berupa mobil dua unit mobil pada satu rumah tangga dan memiliki beberapa unit motor. Hal ini menunjukan bahwa perkembangan perekonomian masyarakat yang semakin meningkat dan adanya aktivitas rutin masing-masing orang memungkin memiliki kendaraan pribadi masing-masing, sehingga hal ini menyebabkan tingkat penambahan volume kendaraan yang setiap saat selalu mengalami peningkatan karena kemudahan untuk mengeluarkan kendaraan atau membeli kendaraan dengan adanya fasilitas kredit, sehigga mempermudah masyarakat untuk memiliki kendaraan.

\subsection{Uji T (Parsial)}

Untuk menguji koefisien regresi dilakukan pengujian secara parsial untuk melihat signifikansi dari pengaruh masing-masing: 
Tabel 1. Coeficient

\begin{tabular}{|c|c|c|c|c|c|}
\hline \multirow{2}{*}{\multicolumn{2}{|c|}{ Model }} & \multicolumn{2}{|c|}{$\begin{array}{c}\text { Unstandardized } \\
\text { Coefficients }\end{array}$} & \multirow[b]{2}{*}{$\mathrm{t}$} & \multirow[b]{2}{*}{ Sig. } \\
\hline & & B & Std. Error & & \\
\hline \multirow[t]{3}{*}{1} & (Constant) & .366 & .490 & .747 & .459 \\
\hline & $\begin{array}{l}\text { Pertumbuhan } \\
\text { Kendaraan }\end{array}$ & .207 & .091 & 2.264 & .028 \\
\hline & Kapasitas Jalan & .814 & .093 & 8.746 & .000 \\
\hline
\end{tabular}

Sumber : Data primer diolah Tahun 2019

Dengan menggunakan analisis regresi berganda pada analisa diatas, maka diperoleh persamaan sebagai berikut:

1. Koefisien regresi peningkatan jumlah kendaraan sebesar 0.207 menunjukkan bahwa pengaruh peningkatan jumlah kendaraan terhadap kemacetan lalulintas di Jalan Perintis Kemerdekaan Kota Makassar adalah positif. Berdasarkan nilai koefisien regresi dapat disimpulkan bahwa peningkatan jumlah kendaraan memberikan pengaruh yang signifikan terhadap kemacetan lalulintas di Jalan Perintis Kemerdekaan Kota Makassar dengan tingkat signifikansi 0.028.

2. Koefisien regresi kapasitas jalan sebesar 0.814 menunjukkan bahwa pengaruh kapasitas jalan terhadap kemacetan lalulintas di Jalan Perintis Kemerdekaan Kota Makassar adalah positif. Berdasarkan nilai koefisien regresi dapat disimpulkan bahwa kapasitas jalan memberikan pengaruh yang signifikan terhadap kemacetan lalulintas di Jalan Perintis Kemerdekaan Kota Makassar dengan tingkat signifikansi 0.000 .

\subsection{Uji F (Signifikan)}

\section{Tabel 2. ANOVA ${ }^{\mathrm{b}}$}

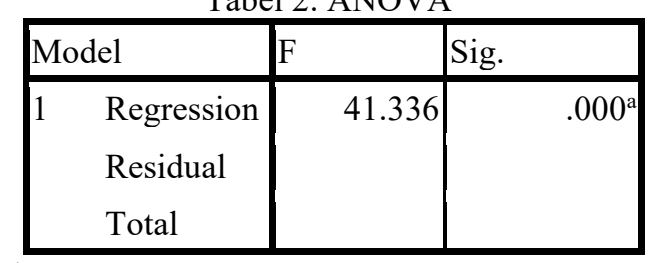

Sumber : Data primer diolah Tahun 2019

Tabel 2 tersebut digunakan untuk menguji apakah secara bersama-sama seluruh variabel independent mempunyai pengaruh yang signifikan terhadap variabel dependent. Dasar pengambilan keputusan dengan taraf signifikansi pada alpha $5 \%$ dengan ketentuan sebagai berikut: (a) Jika Fhitung > Ftabel, maka H1 diterima. (b) Jika Fhitung < Ftabel, maka H1 ditolak. Berdasarkan hasil analis menunjukan bahwa dengan tarap sgnifikasi sebesar 0.000 yang menunjukan bahwa peningkatan jumlah kendaraan dan kapasitas jalan secara bersama-sama berpengaruh terhadap kemacetan lalulintas di Jalan Perintis Kemerdekaan Kota Makassar.

\subsection{Koefisien Determinasi.}

\begin{tabular}{|c|c|c|c|c|}
\hline Model & $\mathrm{R}$ & $\begin{array}{l}\text { R } \\
\text { Square }\end{array}$ & $\begin{array}{l}\text { Adjusted } \\
\text { R Square }\end{array}$ & \begin{tabular}{|l|} 
Std. Error \\
of the \\
Estimate
\end{tabular} \\
\hline 1 & $.789^{\mathrm{a}}$ & .623 & .608 & .679 \\
\hline
\end{tabular}

Sumber : Data primer diolah Tahun 2019

Berdasarkan analisa tabel 4 tersebut, diketahui nilai $\mathrm{R}=0,820$ menunjukkan bahwa peningkatan jumlah kendaraan dan kapasitas jalan memberikan hubungan yang positif terhadap kemacetan lalulintas di Jalan Perintis Kemerdekaan Kota Makassar. Berdasarkan nilai R2 =0,623 atau $62,3 \%$. Hal ini menunjukkan bahwa peningkatan jumlah kendaraan dan kapasitas jalan memberikan kontribusi pengaruh sebesar $62,3 \%$, sedangkan sisanya $37,7 \%$ dipengaruhi oleh faktor lain yang tidak termasuk dalam penelitian ini. 


\subsection{Pembahasan}

Dari analisis hasil penelitian, maka dapat diinterpretasi pengaruh peningkatan jumlah kendaraan dan kapasitas jalan terhadap kemacetan lalulintas di Jalan Perintis Kemerdekaan Kota Makassar sebagai berikut :

\section{Pengaruh peningkatan jumlah kendaraan terhadap kemacetan lalulintas di Jalan Perintis Kemerdekaan Kota Makassar.}

Peningkatan jumlah kendaraan bermotor adalah jumlah kepemilikan kendaraan terus meningkat setiap tahunnya, baik kendaraan roda dua maupun kendaraan roda empat. Indikator yang digunakan pada pengukuran variabel ini adalah: makin tingginya volume kendaraan, permintaan parkir yang meningkat, memanfaatkan jalan sebagai tempat parkir kendaraan, turunnya kapasitas jalan sehingga penggunaan jalan tidak efektif.

Berdasarkan hasil penelitian ini peningkatan jumlah kendaraan berpengaruh positif terhadap kemacetan lalulintas di Jalan Perintis Kemerdekaan Kota Makassar. Kondisi ini terjadi karena pertumbuhan jumlah kendaraan bermotor yang relatif tinggi yang pertumbuhannya terus mengalami kenaikan dari tahun ke tahun sehingga menimbulkan kepadatan lalulintas, kemacetan yang disebabkan oleh banyaknya masyarakat yang lebih memilih untuk menggunakan kendaraan pribadi dibanding kendaraan umum dimana jumlah kendaraan pribadi semakin bertambah setiap harinya.

Konsisten pula dengan Changzhi et al. 2016. Hasilnya menunjukkan bahwa pengaruh luas jalan setiap kepemilikan mobil, berpengaruh signifikan terhadap rasio kemacetan. Analisis sensitivitas juga dilaksanakan untuk mengungkapkan langkah-langkah kebijakan yang lebih efektif dalam mengurangi kemacetan lalu lintas di daerah perkotaan. Jumlah kendaraan bermotor yang bertambah terus mengakibatkan terjadinya kemacetan lalu lintas pada jam-jam sibuk yaitu pada waktu menjelang dimulainya jam kantor dan setelah pulang jam kantor. Kemacetan lalu lintas pada umumnya terdapat didaerah pusat kota dengan keadaan jalan yang sempit dan persimpangan jalan yang tidak beraturan laslu lintasnya. Disetiap kota besar terdapat keluhan mengenai kelambatan, dan kesulitan parkir kendaraan bermotor, serta pemuatan dan pembongkaran muatan barag-barang (Ronal, 2014).

\section{Pengaruh kapasitas jalan terhadap kemacetan lalulintas di Jalan Perintis Kemerdekaan Kota Makassar.}

Kapasitas jalan adalah kemampuan ruas jalan untuk menampung arus atau volume lalu lintas yang ideal dalam satuan waktu tertentu, dengan indikatornya yaitu panjang jalan, lebar jalan, kondisi permukaan jalan, kondisi sarana atau prasarana jalan (lampu lalu lintas dan rambu lalu lintas).

Berdasarkan hasil penelitian ini kapasitas jalan berpengaruh positif terhadap kemacetan lalulintas di Jalan Perintis Kemerdekaan Kota Makassar, kondisi ini terjadi karena lalu-lintas tergantung kepada kapasitas jalan, banyaknya lalu-lintas yang ingin bergerak, tetapi kalau kapasitas jalan tidak dapat menampung, maka lalu-lintas yang ada akan terhambat sehingga menyebabkan kemacetan.

Sejalan dengan hasil penelitian Mustikarani dan Suherdiyanto. 2016. Hasil penelitian sebagai berikut: (1) faktor yang menyebabkan kemacetan lalu lintas faktor jalan (lebaran jalan, volume kendaraan, jarak lampu lalu lintas yang dipasang cukup banyak dan berdekatan dan persimpangan jalan/gang) dan faktor manusia (kegiatan pasar tradisional dan pasar modern, kegiatan parkir sembarangan); dan (2) upaya yang dilakukan untuk dan mencegah, mengurangi kemacetan lalu lintas: memperlebar jalan, membatasi jumlah atau volume kendaraan, menerapan peraturan yang lebih ketat sebagai upaya pencegahan dan pengurangian kemacetan. Sejalan pula dengan hasil penelitian Taiwo (2018) faktor-faktor seperti infrastruktur jalan yang buruk, kapasitas jalan, perdagangan jalanan, parkir di jalan dan persimpangan kapasitas tinggi telah diidentifikasi sebagai penyebab terjadinya kemacetan. Berdasarkan hasil pengamatan kemacetan di jalan koridor Sango-Winners dan di jalan Owode-Iroko antara jam 7 pagi dan 7 malam. Sehingga Studi ini diakhiri dengan merekomendasikan peningkatan dan perluasan jalan untuk mengatasi kemacetan lalulintas. 
Sebagai akibat dari pembuatan jalan raya pada masa yang lalu umumnya adalah sempit, maka usaha untuk mengadakan pelebaran jalan dan pembagian jalur lalu lintas menghadapi banyak kesulitan, disebabkan bangunan gedung terletak sangat dekat ditepi jalan raya. Keadaan semacam ini tedapat diberbagai kota dan pusat-pusat perdagangan. Selanjutnya untuk mengadakan pelebaran jalan ditempat-tempat tersebut tidak ada pilihan lain yaitu pembongkaran bangunan yang terkena pelebaran jalan dan memberikan ganti rugi kepada para pemiliknya, dengan pertimbangan bahwa kepentingan umum harus lebih diutamakan daripada kepentingan perorangan (Rozari, 2015).

3. Pengaruh peningkatan jumlah kendaraan dan kapasitas jalan berpengaruh secara simultan terhadap kemacetan lalulintas di Jalan Perintis Kemerdekaan Kota Makassar.

Meningkatnya kemacetan pada jalan perkotaan diakibatkan bertambahnya kepemilikan kendaraan, banyaknya jumlah kendaraan yang melebihi kapasitas jalan yang menyebabkan kemacetan lalulintas. Pertumbuhan ekonomi yang menyebabkan semakin meningkat intesitas pengguna dan volume kendaraan yang mengakibatkan kepadatan lalu lintas yang sangat tinggi

Peningkatan jumlah kendaraan dan kapasitas jalan berpengaruh secara simultan terhadap kemacetan lalulintas di Jalan Perintis Kemerdekaan Kota Makassar. Hal ini menunjukan bahwajJumlah kepemilikan kendaraan bermotor yang terus mengalami peningkatan yang cukup drastis yang tidak sebanding dengan angka pertumbuhan jalan di Jalan Perintis Kemerdekaan Kota Makassar yang tidak mengalami peningkatan signifikan sehinggga menyebabkan kemacetan di ruas jalan tersebut.

Sejalan dengan pernyataan (Budi, 2014) bahwa jumlah kendaraan bermotor sudah sangat banyak, dan setiap tahunnya bertambah dengan tingkat pertumbuhan yang sangat banyak, meliputi bukan hanya jenis mobil tetapi juga jenis sepeda motor (justru jenis sepeda motor mencapai jumlah yang sangat fantastis). Sedangkan panjang jalan yang tersedia sangat lamban pertambahannya, maka akibatnya adalah terjadinya kemacetan lalu lintas yang mencapai tingkat yang sangat tinggi.

Adanya dampak kemacetan yang ditimbulkan dari sisi ekonomi terlihat jelas bahwa biaya yang dikeluarkan pada saat terkena macet dimana kendaraan melambat atau bahkan berhenti (stuck position). Kondisi jalan yang berhenti membuat pemborosan penggunaan Bahan Bakar Minyak (BBM) karena mesin menyala lebih lama sehingga pengendara harus mengeluarkan biaya yang lebih banyak untuk pembelian BBM, masyarakat yang bekerja juga hilang jam kerjanya karena keterlambatan masuk kerja sehingga akhirnya pendapatan juga ikut mengurang.

\section{PENUTUP}

1. Peningkatan jumlah kendaraan berpengaruh positif terhadap kemacetan lalulintas di Jalan Perintis Kemerdekaan Kota Makassar. Kondisi ini terjadi karena pertumbuhan jumlah kendaraan bermotor yang relatif tinggi yang pertumbuhannya terus mengalami kenaikan dari tahun ke tahun sehingga menimbulkan kepadatan lalulintas.

2. Kapasitas jalan berpengaruh positif terhadap kemacetan lalulintas di Jalan Perintis Kemerdekaan Kota Makassar, kondisi ini terjadi karena lalu-lintas tergantung kepada kapasitas jalan, banyaknya lalu-lintas yang ingin bergerak, tetapi kalau kapasitas jalan tidak dapat menampung, maka lalu-lintas yang ada akan terhambat sehingga menyebabkan kemacetan.

3. Diharapkan oleh Pemprov Kota Makassar untuk mengatasi kemacetan yan terjadi adalah dengan melakukan penguatan transportasi umum dengan meningkatkan perbaikan kinerja pelayanan transportasi umum yang dipandang lebih efektif untuk mendorong masyarakat beralih dari kendaraan pribadi ke transportasi umum.

4. Diharapkan pemerintah Kota Makassar harus mengeluarkan kebijakan untuk membatasi peningkatan jumlah kendaraan bermotor yang ini inti kebijakan ini, harus bisa mengalihkan kebiasaan masyarakat dalam menggunakan kendaraan pribadi ke transportasi umum untuk mengefektifkan kelancaran dalam berlalulintas. 


\section{DAFTAR PUSTAKA}

Badan Pusat Statistik. 2017. Makassar Dalam Angka. Kota Makassar.

Budi Prasetya, Teguh. 2014. Pengembangan Model Transportasi Kota Dalam Menghadapi Tantangan Aglomerasi Kota. Jurnal MAKSIPRENEUR, Vol. IV, No. 1, 2014, hal. 116 - 138.

Changzhi Bian, Changwei Yuan, Wenbo Kuang, dan Dayong WuEvaluation, Classification, and Influential Factors Analysis of Traffic Congestion in Chinese Cities Using the Online Map Data. Mathematical Problems in Engineering Volume 2016, Article ID 1693729, 10 pages.

Firdausi, Dedi. 2016. Pola Kemacetan Lalu-Lintas di Pusat Kota Bandar Lampung. Tesis. Universitas Diponegoro Semarang.

Kurniawan, Y.T, 2017. "Pertumbuhan Kendaraan di Makassar Rata-Rata 7 Persen Setiap Tahun". Warta Ekonomi, 13 Januari 2017

Mustikarani, Wini dan Suherdiyanto. 2016. "Analisis Fator-Faktor Penyebab Kemacetan Lalu Lintas di Sepanjang Jalan H Rais A Rahman (Sui Jawi) Kota Pontianak". Jurnal Edukasi IKKIP PGRI Pontianak Vol. 14 No. 1 Juni 2016.

Manual Kapasitas Jalan Indonesia (MKJl), 1997. Republik Indonesia, Direktorat Jendral Bina Marga, Direktorat Bina Jalan Kota ( Binkot).

Nguyen Van Thu (2016). Scientific Report: "Causes of Traffic Congestion and Solutions" at Vietnam Traffic Safety Conference 2016.

Nguyen Thanh Phong and Le Van Dat (2016).Current situation and solutions to ensure traffic order and safety in industrial zones in Vietnam. Vietnam Traffic Safety Conference Proceedings in 2016.

Nasution, M. Nur. 2004. Manajemen Transportasi. Jakarta: Ghalia Indonesia.

Panjaitan, Pitua Panjaitan. 2017. Faktor-faktor yang mempengaruhi kemacetan lalu lintas kota (studi kasus di dki Jakarta dalam rangka ketahanan kota). Tesis Universitas Indonesia: Jakarta.

Prayogi, Hari. 2011. Kemacetan pada pusat-pusat keramaian di Kota Jakarta Pusat. Universitas Indonesia

Poerwadarminto, W.J.S. 1976. Kamus Umum bahasa Indonesia.Jakarta: Balai Pustaka.

Rozari, Aloisius, Yudi Hari Wibowo. 2015. Faktor-Faktor Yang Menyebabkan Kemacetan Lalu Lintas di Jalan Utama Kota Surabaya. Jurnal Penelitian Administrasi Publik. Vol 1, No 01 (2015)

Ronal, Merza Saputra, 2014. Analisis Perencanaan Penerapan Area Traffic Control System Di Kota Pangkal Pinang. Jurnal Teknik Sipil dan Lingkungan Vol.2.No.3,September 2014. ISSN: 2355-374X.

Taiwo A, Rahman . 2018. Analysis Of Traffic Congestion On Major Urban Roads In Nigeria. 